\title{
A gramática no livro didático de inglês: reflexões no projeto PIBID
}

\author{
Thiago Moreira da Silva \\ UFRJ \\ Rogério Tilio \\ UFRJ
}

\begin{abstract}
Resumo
Ensinar gramática na escola é, frequentemente, focar na estrutura. Neste trabalho analisaremos, tendo como orientação a teoria sistêmico-funcional (HALLIDAY \& HASAN, 1989), como este ensino é proposto no livro didático usado pela professora supervisora do projeto PIBID (CAPES) em sala de aula, triangulando esta análise com questionário respondido pela docente.
\end{abstract}

Palavras-chave: ensino de gramática, linguística sistêmico-funcional, PIBID

\begin{abstract}
Teaching grammar at school frequently means focusing on structure. In this paper, using the systemic-functional theory (HALLIDAY \& HASAN, 1989), we analyze how this teaching is proposed in the coursebook used by the PIBID (CAPES) supervisor in her classes. We compare the analysis with a questionnaire answered by the teacher.
\end{abstract}

Key words: grammar teaching, systemic-functional linguistics, PIBID.

\section{INTRODUÇÃO}

O status que a gramática ocupa no ensino das línguas na escola, tanto no ensino de Língua Portuguesa como no de Língua Estrangeira, pode e deve ser problematizado. A abordagem adotada pelos professores tende a ser frequente e demasiadamente estrutural, com a maior parte do foco sendo direcionado à estrutura da língua, ou seja, às regras gramaticais. O problematizar aqui proposto não tem por objetivo refutar ou desmerecer a importância do ensino dessas estruturas gramaticais. Sabe-se que estas estão intimamente ligadas com o modo com que o falante opera no mundo através do discurso. Saber operar com essas estruturas é saber organizar, compor a materialidade linguística em forma de textos, sejam eles orais ou escritos, de forma a (inter)agir no mundo social (HALLIDAY \& HASSAN, 1989).

\footnotetext{
${ }^{1}$ Agradecemos à CAPES pela concessão de bolsas PIBID ao subprojeto Letras-Inglês da UFRJ, que possibilitaram a realização dessa pesquisa.
} 
Com base nas elucidações trazidas para o estudo da linguagem por meio das teorizações da Linguística Sistêmico-funcional (HALLIDAY \& HASAN, 1989), constata-se a importância das formas linguísticas na veiculação de significados. A questão conveniente de ser levantada aqui é a maneira como essas formas estão sendo ensinadas para os alunos. $\mathrm{O}$ foco está sendo dado à forma por si só, como um fim, ou à forma relacionada às suas funções, como um meio para se construir possíveis significados (meaning potential, nas palavras de Halliday)? Se o foco está somente na estrutura, isso se deve ao professor? Ao livro didático? Com o objetivo de (re)pensar essas perguntas em um contexto bem específico é que este trabalho foi desenvolvido.

O intuito aqui, portanto, é problematizar, à luz da teoria sistêmico-funcional, que considera a linguagem atrelada ao seu uso (HALLIDAY \& HASSAN, 1989) como o livro didático de inglês utilizado em uma escola da rede estadual de ensino do Rio de Janeiro participante do Projeto Institucional de Iniciação a Docência (PIBID/CAPES/UFRJ) - Upgrade, volume 3 (Editora Richmond, 2012) - aborda questões gramaticais. Mais especificamente, será analisada a unidade 6, cujo tópico gramatical é a voz passiva. Após a análise, os resultados são triangulados com o discurso da professora regente participante do projeto PIBID, no status de supervisora dos licenciandos, que utiliza o livro didático em questão em sua prática pedagógica. Os dados referentes ao discurso da professora foram gerados a partir de um questionário, e sua triangulação com a análise do livro didático enquanto documento pedagógico tem como objetivo perceber se a perspectiva do livro didático em relação à abordagem gramatical é de natureza estrutural, e se o discurso da professora em questão corrobora com ou desconstrói a visão que o livro traz.

Importante ressaltar ainda que as turmas que utilizam o livro didático em questão são de Ensino Médio. Essa constatação deve remeter a um pensar que também considera as Orientações Curriculares para Ensino Médio (BRASIL, 2006), que ressaltam a importância de um ensino da língua considerando a esfera do social, em que esta circula, e o desenvolvimento de um pensar crítico da sociedade em que o aluno está inserido, instrumentalizando-o a promover transformações no ambiente sociocultural, ou seja, deve-se levar em conta a perspectiva de Letramento Crítico (BRASIL, 2006) na análise. 


\section{FUNDAMENTAÇÃO TEÓRICA}

A visão que norteia este trabalho não concebe a gramática apenas como um conjunto sistematizado de regras estanques, fora de qualquer contexto. Antes, a perspectiva aqui adotada é a da gramática sob uma perspectiva sistêmico-funcional (DOWNING \& LOCKE, 2006; HALLIDAY \& HASAN, 1989; HALLIDAY \& MATTHIESSEN, 2004). Nesta linha de pensamento, a gramática abarca três tipos de significado: experiencial/ideacional, interpessoal e textual. Respectivamente, o primeiro dos três significados faz referência ao uso que fazemos da materialidade linguística para construir a realidade ao nosso redor; este significado está relacionado à expressão de nossas conceptualizações, no tocante às nossas experiências, sejam elas reais ou imaginárias. O segundo faz referência a como usamos a linguagem para interagir com o outro, influenciando suas ações, fazendo algo no mundo social em que circulamos. Já o terceiro diz respeito à materialidade linguística em si, a como o discurso se materializa, ou seja, nossas escolhas lexicais, sintáticas e assim por diante. Ao invés de tratar a gramática como um conjunto de formas, a teoria aqui adotada a trata como um construto destes três significados que se alimentam e ocorrem mutuamente.

Uma vez que o material a ser analisado é um livro didático, recorreu-se ao modelo teórico proposto por Tilio (2013), que coloca em diálogo os três tipos de significado propostos por Haliday \& Hasan (1989) - ideacional, interpessoal e textual - e os três elementos constitutivos dos gêneros do discurso, segundo Bakhtin (1952 [2003]) conteúdo temático, estrutura composicional e estilo -, uma vez que o livro didático é aqui entendido como um gênero discursivo. Propomos, portanto, a utilização do modelo acima para delinear as categorias para análise do livro didático em questão.

Alinhado a teoria linguística de base sistêmico-funcional e com os conceitos de gêneros discursivos, multiletramentos, contemporaneidade e Linguística Aplicada contemporânea, o livro didático pressupõe três dimensões da linguagem (adaptado de TILIO \& ROCHA, 2009):

- Ideacional-temática, que representa e constrói experiências e a realidade social;

- Interpessoal-composicional, que estabelece relações sociais e de poder entre os interlocutores da prática discursiva; e

- $\quad$ Textual-estilística, que organiza e estrutura o discurso linguística e formalmente. 
Ainda, uma vez que o tópico gramatical em questão é o da voz passiva, era imprescindível saber o que as gramáticas da língua inglesa, sejam de perspectiva mais tradicional ou mais funcional, tinham a dizer. O ponto de acordo entre elas é do significado mais nuclear da voz passiva: o apagamento do foco no agente da ação, uma vez que este é removido da posição inicial da sentença, não estando mais na posição de Tema (HALLIDAY \& MATTHIESSEN, 2004). Ou seja, o agente não é mais o ponto de partida da mensagem; ele se torna parte do desdobramento dela, daquilo que é dito sobre o Tema, ele em si não ocupando mais tal posição (BIBER et al, 1999; CELCE-MURCIA \& LARSEN-FREEMAN, 1999; DOWNING \& LOCKE, 2006; HALLIDAY \& MATTHIESSEN, 2004).

A questão central é que a escolha da voz passiva dá margem a significados diferentes daqueles trazidos à interação pela voz ativa. Essa escolha ganha implicações decisivas nas interações sociais e - mesmo que de maneira inconsciente - o falante do Inglês, ou de qualquer outra língua, considera o uso que melhor servirá a seus propósitos de interação.

Têm-se, então, duas perspectivas dicotômicas para o ensino de gramática: uma estruturalista e outra funcionalista. Na perspectiva estruturalista, as formas linguísticas são apresentadas desnudas do elemento social. Na vida social do aluno, a materialização dessas formas linguísticas na linguagem está atrelada ao seu uso em sociedade, não está isolada no vácuo social (WERTSCH, 1991). Na perspectiva estruturalista, as formas linguísticas pré-existem aos seus usos sociais, em uma esfera acima do uso contextualizado, como se os usos estivessem subordinados a essa esfera da norma. O que não se percebe ao se adotar essa perspectiva é que, diferentemente do concebido, o uso deve ser apresentado aos estudantes de modo a instrumentalizá-los para agirem socialmente. As formas servem a realização de propósitos/funções maiores, sem as quais não faz sentido a memorização de estruturas e sua posterior cobrança em uma prova. As formas linguísticas precisam ser entendidas pelos alunos como recursos dos quais eles devem se apropriar conscientemente, com o objetivo de agirem na sociedade como cidadãos empoderados (NICOLAIDES \& TILIO, 2011).

Do outro lado, a perspectiva funcionalista considera as escolhas das formas linguísticas sempre relacionadas aos seus usos, ou seja, às suas funções e ao seu potencial 
de criadoras de significados. Assim, as escolhas gramaticais remetem sempre às situações em questão, dialogando com conjunturas e discursos que antecedem o discurso materializado nestas escolhas.

Sendo assim, colocar a forma gramatical em quadros, como faz o livro analisado, desprovidas de contexto, caracteriza uma abordagem estrutural que, pela ausência de credibilidade social, ou seja, de ligação com a realidade social do aluno, não favorece o letramento crítico.

\section{METODOLOGIA}

Como já mencionado anteriormente, o objetivo deste trabalho é analisar como a parte sistêmica da língua, mais especificamente, a gramática, é abordada pelo livro didático Upgrade, volume 3 (Editora Richmond, 2012). O intuito é perceber se o conhecimento sistêmico é desvinculado dos conhecimentos de mundo e textual (BRASIL, 1998), altamente necessários para uma compreensão macro da linguagem. Ou seja, o resultado esperado era identificar se o ensino da forma linguística é abordado em uma perspectiva estruturalista, micro (somente o sistêmico) ou funcionalista, macro (considerando o contexto em que essa circula, bem como seu papel em unidade maior: o discurso).

Para viabilizar o alcance deste objetivo, foi utilizado o construto de análise proposto por Tilio (2013), que se vale das três esferas de significado da teoria sistêmico funcional, como três categorias de análise para o livro didático, a fim de perceber se estas são levadas em conta ou não no material em questão. A unidade analisada foi a unidade 6, Fighting the flu.

O livro didático, na concepção proposta por Tilio (2013), é entendido como uma unidade discursiva, e da mesma forma o são as suas unidades. Deste modo, torna-se viável a aplicação das categorias baseadas nos significados textual, interpessoal e ideacional para a análise de livros didáticos. Embora Halliday \& Hasan (1989) tenham concebido sua teoria com vistas à análise gramatical do texto, ela também pode ser expandida à análise de livros didáticos, uma vez que esses também se configuram como textos. 
Sabe-se que, assim como o livro se apresenta como um participante muito importante no processo de aprendizagem, o mesmo precisa ser dito sobre o professor. $\mathrm{O}$ ideal para um ambiente propício ao sucesso da aprendizagem é ter-se um livro de qualidade e um professor com uma formação igualmente densa em qualidade. Por um livro de qualidade, entende-se aqui aquele que propicia não somente a exposição dos alunos a estruturas de uma determinada língua (significado textual), mas também traz temas socialmente relevantes e problematiza o que estas estruturas operam nestes contextos específicos (significado ideacional), e possibilita interações dos aprendizes com o meio social (significado interpessoal) pelo uso da língua-alvo.

Para que tal dinâmica crítica se concretize, é importante que o professor explore os temas trazidos pelo livro de forma a expandir os horizontes do aluno. Por essa razão, estão triangulados no presente trabalho os dados da análise documental do livro didático com a análise da resposta a um questionário de sete perguntas, redigida por uma professora que utiliza o livro em sua sala de aula. Esta é uma professora da rede estadual de ensino do Rio e Janeiro, participante do projeto PIBID/UFRJ de língua inglesa, financiado pela CAPES.

As perguntas que orientaram a análise do livro foram as seguintes:

- Que crenças são percebidas através da abordagem do livro no que diz respeito ao ensino da voz passiva?

- $\quad$ O ensino de gramática visa a possibilitar uma interação mais eficiente dos aprendizes na sociedade?

- $\quad$ Como a forma da voz passiva se relaciona com o seu significado no livro?

- Que perspectiva é adotada no ensino de gramática, mais especificamente, no ensino da voz passiva?

- Há alguma tentativa de contextualizar os usos gramaticais com as práticas sociais?

As perguntas dirigidas à professora, através de um questionário, foram as seguintes:

- Qual o papel do ensino de gramática na aprendizagem de uma língua estrangeira?

- $\quad$ Percentualmente, qual o espaço da gramática nas suas aulas?

- $\quad$ O que você acha da forma como o livro didático trabalha a gramática? 
- Você diria que os seus alunos alcançam êxito na aprendizagem da língua? Por quê? Você acha que a gramática contribui para isso?

- Como os seus alunos reagem ao ensino de gramática?

Estas questões tiveram a função de orientar a análise que será apresentada na seção a seguir. O trabalho foi, durante todo o tempo, um exercício na direção de encontrar respostas, elucidações para tais questões.

\section{RESULTADOS}

De forma esquemática, a análise da unidade do livro didático apresentou os seguintes resultados (cf. Figura 1):

\begin{tabular}{|c|c|c|}
\hline Metafunção & Unidade & Gramática \\
\hline $\begin{array}{l}\text { Experiencial/ } \\
\text { ideacional }\end{array}$ & $\begin{array}{l}\text { Em linhas gerais, Saúde é o } \\
\text { tema central da unidade. No } \\
\text { entanto, esta traz também } \\
\text { um texto sobre Seattle, e } \\
\text { diversas frases aleatórias, } \\
\text { sem qualquer } \\
\text { comprometimento com o } \\
\text { suposto conteúdo temático } \\
\text { da unidade - ou com } \\
\text { qualquer outra } \\
\text { contextualização. }\end{array}$ & $\begin{array}{l}\text { Não há. É apresentada apenas } \\
\text { uma frase - retirada do texto } \\
\text { inicial da unidade - com o intuito } \\
\text { de "contextualizar" o ensino da } \\
\text { estrutura gramatical. As demais } \\
\text { frases utilizadas na abordagem } \\
\text { gramatical (apresentação e } \\
\text { atividades), à exceção de uma, } \\
\text { descontextualizada, sequer } \\
\text { referem-se ao suposto conteúdo } \\
\text { temático da unidade. } \\
\text { A gramática é apresentada e } \\
\text { trabalhada de forma puramente } \\
\text { estrutural sem dar conta das } \\
\text { possíveis implicações sociais } \\
\text { decorrente de seu uso. Há uma } \\
\text { tentativa incipiente de se } \\
\text { trabalhar o USO da estrutura, que } \\
\text { acaba recaindo } \\
\text { predominantemente no foco na } \\
\text { forma. }\end{array}$ \\
\hline
\end{tabular}




\begin{tabular}{|c|c|}
\hline Interpessoal & 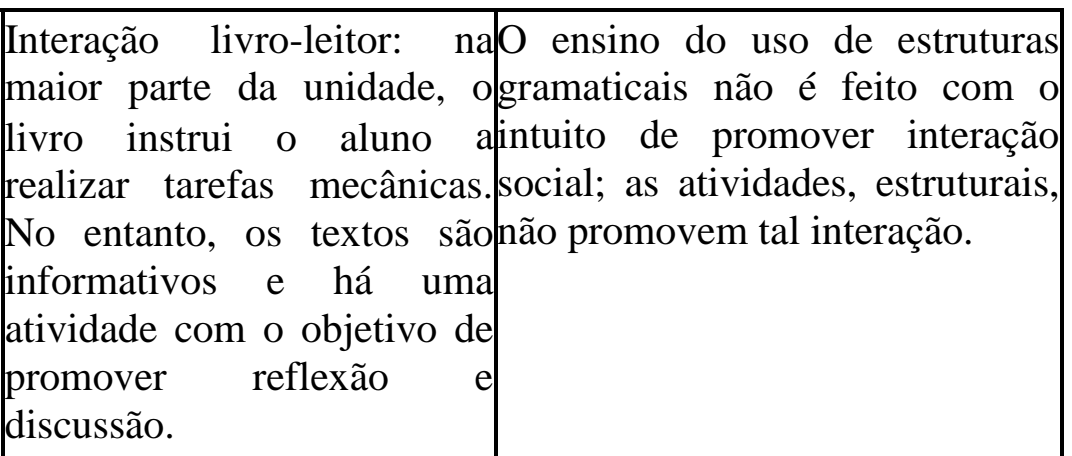 \\
\hline Textual & \begin{tabular}{|l|ll|}
$\begin{array}{l}\text { Organização estrutural da } \\
\text { unidade: texto, vocabulário, } \\
\text { gramática, texto e texto. }\end{array}$ & $\begin{array}{l}\text { gramatical: } \\
\text { estruturas em caixas, }\end{array}$ \\
& aprática estrutural.
\end{tabular} \\
\hline
\end{tabular}

Figura 1: Resultado da análise da unidade 6 do livro didático Upgrade 3.

À luz do conceito de Tema (HALLIDAY \& MATTHIESSEN, 2004), seria de se esperar encontrar a apresentação da gramática e atividades a ela relacionadas que realmente formassem uma unidade semântica com o tema (conteúdo temático) da unidade. Em linhas gerais, essa tentativa foi percebida, porém de forma bastante tímida. É verdade que algumas frases utilizadas na apresentação gramatical são retiradas de textos da unidade, ou remetem semanticamente ao seu tema. No entanto, isso não é suficiente para caracterizar uma contextualização do ensino da gramática. Além disso, as diferenças entre as nuances de significado da voz passiva e da ativa não foram enfatizadas nas atividades, puramente estruturais.

Na esfera interacional, o livro não promove uma conscientização dos significados que podemos construir no mundo através do uso das estruturas. Seus exercícios são compostos de, por exemplo, frases na voz ativa para que o aluno as reescreva na voz passiva, com a finalidade de praticar o domínio da estrutura, apenas. Não há um contexto significativo para o aluno, em que os contrastes semânticos possam ser abordados e problematizados dentro de uma perspectiva de interação com o outro. Ou seja, como essas estruturas podem ser usadas para "falar" com o outro, influenciando em suas ações, não é levado em conta.

No tocante ao significado ideacional e ao letramento crítico, existem algumas atividades que promovem uma discussão que vai além do nível da leitura crítica. Estas, porém, contemplam somente o tema da unidade, isolando a gramática desta dinâmica de discussão. 
Como resposta às perguntas acima mencionadas na seção Metodologia, conclui-se que, na visão implícita no livro:

- $\quad$ O ensino da voz passiva é organizado de forma estrutural;

- $\quad$ A instrumentalização do aluno para melhor agir em seu ambiente social não é levada em conta apropriadamente;

- $\quad$ A estrutura não está devidamente vinculada às práticas sociais;

Vale ressaltar que as atividades estruturais podem sugerir ao aluno que a voz passiva está diretamente subordinada à ativa, sendo aquela uma variação desta. A respeito deste equívoco, Celce-Murcia \& Larsen Freeman (1999) destacam que a voz passiva não é meramente uma variação sintática da ativa, antes, elas são usadas por razões diferentes. Ainda segundo as autoras, apresentar o recurso da voz passiva como variante da ativa é induzir o aluno ao equívoco; existem casos em que o emprego da voz passiva é apropriado em detrimento da voz ativa. O livro didático não reforça essa informação importante em nenhum momento (CELCE-MURCIA \& LARSEN FREEMAN, 1999).

Voltaremos nossa atenção, a seguir, para o discurso da professora em questão:

\begin{abstract}
Pensando no ensino de gramática na aprendizagem de uma língua estrangeira, um dos aspectos mais comuns e complicados observados é a turma heterogênea, um grande problema, principalmente nas escolas públicas. Contudo, com duas aulas por semana, uma tem que ser de gramática, quando o aluno é levado a aprofundar seu conhecimento sistêmico da língua inglesa por meio de explicações simples, que levam à observação e à compreensão de como a língua se organiza estruturalmente. Escolhemos o livro Upgrade da Richmond onde a gramática é apresentada de forma contextualizada, com as diferentes situações de uso da língua por meio de exemplos que possibilitam a inferência da forma a partir do sentido. Quanto ao êxito na aprendizagem da língua é muito individual, o professor tem que ter a sensibilidade para perceber que determinado aluno está ou não com dificuldades para a aprendizagem da língua e ajudá-lo no que ele precisar, principalmente na timidez que atrapalha muito. Particularmente, acredito que a gramática tem um papel especial na aprendizagem da língua quando o aluno percebe o papel fundamental de um pronome ou de um verbo. E percebendo essas funções o entendimento fica mais claro.
\end{abstract}

Algumas das crenças da docente podem ser aqui inferidas. Por exemplo, ao afirmar que uma das aulas leva "à observação e à compreensão de como a língua se organiza estruturalmente", ela eleva a organização estrutural do idioma à posição de produto final de sua aula. Ainda, ao declarar que o livro foi escolhido por conter “exemplos que possibilitam a inferência da forma a partir do sentido", demonstra a 
importância do ensino da forma em suas aulas. Na verdade, no mundo social, os textos são compostos de significados (HALLIDAY \& HASAN, 1989), tendo a forma o único objetivo de construir sentido - ou seja, é a forma que colabora na construção do sentido, e não o sentido que determina a escolha da forma. $\mathrm{O}$ foco final de suas aulas é, portanto, estrutural. Ao invés de levar o indivíduo a pensar criticamente, todo o esforço da professora parece ser direcionado apenas à estrutura, quando ela afirma que o papel da gramática está em o aluno "perceber o papel fundamental de um pronome ou um verbo".

\section{CONSIDERAÇÕES FINAIS}

Ao analisarmos o livro didático e o discurso da professora que o utiliza, pode-se perceber que a visão da docente converge com a abordagem estrutural da gramática contida no livro didático. Isso sugere não somente repensar as posições assumidas dentro de tudo que foi aqui levantado, mas também, de igual forma, voltar-se para o professor, para a sua formação (continuada), de forma que ele possa efetivamente trabalhar para promover a formação de cidadãos conscientes do uso que fazem do discurso nas práticas sociais em que estão inseridos. Trata-se, também, de empoderar o aluno a analisar de forma crítica as trocas que são estabelecidas entre ele e os outros indivíduos. Deve-se levar em consideração o ciclo que essa nova prática de reflexão poderá gerar, uma vez que a formação que o aluno recebe hoje é a formação que ele vai repercutir como professor, ou em qualquer outra área profissional, no futuro, visto que a linguagem perpassa todas as esferas de nossa experiência.

\section{REFERÊNCIAS}

BAHKTIN, M. [1952] Os gêneros do discurso. In: BAHKTIN, M. [1979]. Estética da criação verbal. 4. ed. Rio de Janeiro: Martins Fontes, 2003.

BIBER, D.; JOHANSSON, S.; LEECH, G.; CONRAD, S.; FINEGAN, E. Longman Grammar of Spoken and Written English. London: Longman, 1999.

BRASIL. Ministério da Educação, Secretaria De Educação Básica. Orientações curriculares para o ensino médio. Volume 1: Linguagens, códigos e suas tecnologias. 
Brasília, 2006. p. 18-46. Disponível em:

http://portal.mec.gov.br/seb/arquivos/pdf/book_volume_01_internet.pdf. Acesso em 04/07/2010.

BROWN, H. D. Teaching by principles: an interactive approach to language pedagogy. 3. ed. London: Longman, 2007.

BRASIL. Ministério da Educação, Secretaria de Educação Fundamental. Parâmetros curriculares nacionais: terceiro e quarto ciclos do ensino fundamental: língua estrangeira. Brasília, 1998. Disponível em:

http://portal.mec.gov.br/seb/arquivos/pdf/portugues.pdf. Acesso em 04/07/2010.

CELCE-MURCIA, M.; LARSEN-FREEMAN, D. The Grammar Book: an ESL/EFL teacher's course. 2. ed. Boston: Heinle \& Heinle, 1999.

DOWNING, A.; LOCKE, P. English Grammar: a university course. 2. ed. London, NY: Routledge, 2006.

HALLIDAY, M.A.K.; MATTHIESSEN, C.M.I.M. An Introduction to Functional Grammar. 3. ed. London: E. Arnold, 2004.

HALLIDAY, M. A. K.; HASAN, R. Language, context and text: aspects of language in a social-semiotic perspective. Oxford: Oxford University Press, 1989.

NICOLAIDES, C.; TILIO, R. O material didático na promoção da aprendizagem autônoma de línguas por meio do letramento crítico. IN: SZUNDY, P. et. al. (Orgs.) Linguística Aplicada e sociedade: ensino e aprendizagem de línguas no contexto brasileiro. Campinas: Pontes, 2011.

TILIO, R. Linguística (Aplicada), contemporaneidade e materiais didáticos: diálogos. In: SANTOS, L. I.; SILVA, K. A. (Orgs.) Linguagem, ciência e ensino: desafios regionais e globais. Campinas: Pontes, 2013.

TILIO, R.; ROCHA, C. H. As dimensões da linguagem em livros didáticos de inglês para o Ensino Fundamental I. Trabalhos em Linguística Aplicada, Campinas, 48(2), p. 295315, Jul/Dez 2009. ISSN 0103-1813. Disponível em:

http://www.scielo.br/scielo.php?pid=S0103-18132009000200008\&script=sci_arttext. Acesso em 10/07/2010.

WERTSCH, J. V. Voices of the mind. Cambridge, Massachussetts: Harvard University Press, 1991. 


\section{OS AUTORES}

Thiago Moreira da Silva

E-mail: thiago.letras.ufrj@gmail.com

Rogério Tilio, Doutor, UFRJ

E-mail: rogeriotilio@letras.ufrj.br 